\title{
Anatomic features of horse and manchurian wapiti
}

\author{
Nadezhda Momot ${ }^{*}$, Yulia Kolina, Igor Kamliya, Svetlana Terebova and Tatiana Timofeeva \\ Primorskaya State Agricultural Academy, 692510 Ussuriisk, Russia
}

\begin{abstract}
Carrying out a sanitary and veterinary expertise is a mandatory requirement which is necessary for the admission of livestock products, meat in particular, to sale. When carrying veterinary and sanitary expertise we often come up the attempts of meat products adulteration, for example when livestock meat is replaced to wild one and vice versa. Most often such adulteration cases are the results of illegal hunting. The purpose of our work is study horse and Manchurian wapiti carcasses anatomic features. The main methods of meat species determine are analysis of carcass appearance, organoleptic parameters analysis, laboratory tests as well as analysis and feature examination of anatomic structure of the inspected carcass. To determine meat species we applied methods of comparative and anatomic examination, organoleptic parameters analysis of meat samples, and laboratory tests. The suggested methods of examination can be used not only for determination of the whole animal carcasses species, but for small parts of the body. It is of great importance in conducting forensic and veterinary researches, when the number of parts can be finite. Maximal efficiency can be achieved only with complex use of enumerated methods.
\end{abstract}

\section{Introduction}

Conducting veterinary and sanitary expertise of animals' body is the mandatory requirement to sale and use animal products. Veterinary and sanitary expertise determines quality of the inspected product, certificate on using this product for a variety of ends is given on the base of it. The important part of veterinary and sanitary expertise of meat products is detection of possible adulteration, that is substitute of more expensive meat by less expensive one [1-16]. The attempts to pass wild animal meat as for livestock one can happen after illegal hunting, when wild animal meat was taken by illegal means. Besides, in some cases domestic animal can be killed instead of wild one on hunting by chance, especially because of pure visibility. For example, we have the information about the hunting case when at night the shadow figure of horse was confused with a shadow figure of female Manchurian wapiti. As a result, the horse was killed by illegal hunters. As for information about anatomical organization of wild animals' carcasses, it is scare, fragmentary and often contradictory in accessible sources.

\footnotetext{
*Corresponding author: momot18@mail.ru
} 
The purpose of our research is study specific features of horse and Manchurian wapiti carcasses appearance.

\section{Materials and methods}

Subjects of the research were the carcasses of Manchurian wapiti, which were brought to the Animal disease diagnostic center of Primorskaya State Agricultural Academy for carrying out an expert examination. Carcasses of horses were examined on private farms in Ussuriisk district during regular slaughter. Three carcasses of each species were inspected. Methods of anatomization and examination were used as the main one. The main methods of meat species determine are analysis of carcass appearance, organoleptic parameters analysis, laboratory tests as well as analysis and feature examination of anatomic structure of the inspected carcass.

\section{Results and discussion}

Carcass appearance.

It is quite easy to determine meat species of the whole carcass or of half carcass.

Carcass of Manchurian wapiti, as that one of most deer, is massive, has broad chest and well developed coupling. Neck is broad, short, subcutaneous tissue on neck has little edipose even in thick fleshed animals, outlines of tuber ishii are clean cut.

Carcass of horse is delicately shaped, thoracic section is elongate, cone-shaped. Coupling is shorter that thoracic section. Carcass has long, relatively deer neck, it subcutaneous tissue has well developed adipose and connective tissue. Rump is bulging, head of femur outlines are smoothed $[4,6]$.

Organoleptic parameters.

Identification of meat species with the help of organoleptic parameters analysis is used when it is impossible to conduct an examination of the whole carcass or a half. An expert should have great experience in conducting veterinary and sanitary expertise for accurate analysis. It should be noted, that organoleptic parameters greatly depend on sex and age of animal. Thus, meat of young animals and females is lighter in color than that of males and old animals. Besides, meat becomes lighter in time. Meat that was frozen and unfrozen several times is darker than meat that undergoes freezing once. Using organoleptic parameters, attention should be paid to color and smell of meat, as well as degree of muscular fiber manifestation.

Manchurian wapiti meat is dark red from light to dark shades. There is relatively little adipose tissue. There is much adipose in Manchurian wapiti females, who was killed in the period of pregnancy. Adipose is white or light yellow color, firm texture, crumble easily.

Horse meat: has darker color by comparison with meat of deer, its color is almost brown, and after keeping on air up to black-red with bluish shade. Its adipose is characterized with more intensive yellow color by comparison with cow's and has softer texture. An important feature typical for horse meat is high degree of muscular fiber, it is shown through much grain of meat on slice compared to Manchurian wapiti meat.

Identification of meat species with the help of smell analyses is possible not always and great experience of expert is supposed in such case. Only fresh meat is used for the examination. It is impossible to identify any meat species by smell analyses after freeze and following defrosting.

Laboratory methods.

Laboratory methods of meat species identification include measuring fat melting point and precipitation test. 
Measuring fat melting point can provide differentiation of Manchurian wapiti meat from horse meat, as fat of the pointed meat species has significant difference in melting point. Manchurian wapiti fat melting point is $47-52 \mathrm{o}$ C, horse fat melting point is about $30 \mathrm{o} \mathrm{C}$.

Precipitation test is carried out by mixing of examined meat extract with precipitated serum received from the definite species of animal. For Manchurian wapiti identification, precipitated serum of cattle can be used.

Skeletal pattern particularities.

Anatomic organization analysis of skeleton certain parts is the most accurate method of meat species identification, because the organization of all anatomical structures in certain animal species has the pattern particularities specific only for this given animal. In our work we deem it expedient to turn our attention to the particularities of those skeleton bones, which have more distinct species anatomical features and are obtainable for examination.

Axial skeleton.

Cervical spine. Manchurian wapiti has short cervical vertebra, dorsal crista of the second cervical vertebra is distinctively separated from caudal articular processes, spinous processes of medium cervical vertebrae are well-marked. Horse has long vertebrae of cervical spine, dorsal crista of the second cervical vertebra is divided into two halves and passes into caudal articular processes without visible bounds. Spinous processes of medium cervical vertebrae are greatly reduced.

Thoracic section. Manchurian wapiti's thoracic section consist of 13-14, rarely 15 thoracic vertebrae. Vertebrae spinous processes have keen edge, a top of spinous process is piked. Ribs are wide, their wideness increase to ventral part and is about 2-2.5 times more that in dorsal part. Breast bone is flattened to dorsoventral part, so it has a form of massive sheet with increased wideness to caudalis and has well-marked xyphoid process and xyphoid cartilage. A horse has 18-19 thoracic vertebrae in thoracic section. Spinous processes have piked cranial edge and widened caudal edge. The pick of spinous process is thick. Width of ribs is much the same along the entire length. Breast bone is flattened from the sides and therefore is acute V-shaped. There is a ventral crista on the ventral surface of breast bone. Xiphoid cartilage is well-developed, while xyphoid process is pure-developed.

Lumbar spine. Lumbar spine of a Manchurian wapiti consist of 5, sometimes 6, lumbar vertebrae. Transverse processes of vertebrae have irregular edges, articular surface of cranial articular processes have channel-shape, caudal ones are cylinder-shaped.

A horse has 6 , sometimes 5, lumbar vertebrae. The edges of transverse processes of vertebrae are regular, articular surface of cranial and caudal articular processes are flat. Final lumbar vertebrae of a horse join together and with sacral bone not only with articular processes but with articular surface, which is situated on the edges of transverse costal processes.

Sacral section. It is presented by sacral bone formed with concrescent sacral vertebrae. Sacral bone of a Manchurian wapiti consist of 5 sacral vertebrae, spinous processes of nearest vertebrae are completely grown together and form dorsal crista. Sacral bone of a horse also consist of 5 , sometimes 6 , concrescent sacral vertebrae, but there is no concrescence between spinous processes.

Distal skeleton.

Skeleton of thoracic limb. Scapula of Manchurian wapiti in the place of scapula spine has an evident angle (acromion), which is formed by spine at the neck of scapula upon a glenoid cavity.

A horse has no acromion, because scapula spine at the neck of scapula reduces highness gradually. There is well-defined spine crista on a scapula spine.

Scapula bone of Manchurian wapiti in the field of proximal epiphysis has two cristae lateral and medial. Lateral crista is developed better and overhang above intercristae canal. 
Proximal epiphysis of a horse has three cristae - lateral, medium and medial, which are developed much the same. Due to medium crista, intercristae canal forks.

Forearm skeleton. It consist of two bones - radial and ulnar. In angulate animals due to loss of multifunctionality of limbs, there is reduction of ulnar bone and it's combining with radial one. In Manchurian wapiti ulnar bone goes with radial all along. In horse only ulnar bone crista is well defined. Body of ulnar bone is greatly reduced and is defined only in proximal third part of a radial bone. Ulnar bone is fully reduced to the distal part.

Pelvic limb skeleton. Pelvic bones are represented by suprailiac, pubic and ischial bones, which form pelvic bone after growing together, which include glenoid cavity and foramen obturatum. Right and left pelvic bones when growing together on pelvic rhaphe, are forming bony pelvis. Pelvic limb of Manchurian wapiti is cylindrical, sitting bone has three cristae.

Horse hip bone is cone-shaped, on ischial bone sitting bone is divided into two cristae.

Femoral bone. Femoral bone of Manchurian wapiti near proximal epiphyses has two trochanters - big and small one. There is a foveation on a femoral head - fossa of a head, which serves for the attaching of round ligament (fig. 15A).

There are four trochanters - big, small, medium and third - on a horse femoral bone. There is a triangular incisure on a femoral head for the attaching of round ligament.

Bones of the crus. Crus of ungulate animals is presented only by shinbone. Peroneal bone is greatly contracted or is absent. There is a peroneal process near the ectocondyle of Manchurian wapiti, which is vestigial structure of peroneal bone. Joint blockage of distal epiphyses is straight directed.

Articular surface of peroneal bone in horse is situated near ectocondyle of a shinbone, vestigial structure of peroneal bone is attached to it, which is a thin bone sheet notable near proximal third part of shinbone. Joint blockage of shinbone distal epiphyses has significant oblique cross course.

We don't take into consideration the anatomical features of extremities distal part skeleton in our work. It is based on the fact, that from the one hand the identification of species on the enumerated parts is not difficult because of the evidence of specific species features. From the other hand, these sections have no any significance in meat species identification in the practise of veterinary and sanitary expertise. The significant particularity of all tubular bones of a horse is the presence of thin bone interseptum in distal epiphyses in particular in bone marrow cavity, they pass throw the depth of bone marrow and subdivide the bone marrow cavity into chambers. Due to the interseptums, it is difficult to get bone marrow from the medullary cavity of a horse. There are no interseptums in Manchurian wapiti, so it is quite easy to get bone marrow from the cavity.

Internal organs structure particularities.

Tongue. Manchurian wapiti has rough, often pigmented tongue, the tip of it is round, there is increase in thickness on its back - a roller.

A horse has a long tongue, its tip is flat, it's back is covered with thick layer of keratinized epithelium.

Liver. In Manchurian wapiti the lobes of a liver is pure expressed, there is no oesophageal incisures and gallbladder.

Liver of a horse has three lobes and deep oesophageal incisures, but there is no gallbladder.

Kidneys. Kidneys of Manchurian wapiti are smooth and one-papillary on structure. Right and left kidneys are similar bean-shaped and almost equal in size.

Kidneys of a horse are also smooth and one-papillary, so their surface is smooth, right kidney is heart-shaped, left one is bean-shaped.

Spleen. Manchurian wapiti has flat, broad spleen, it is oval-shaped in transverse section. 
Horse has arched spleen with its broad and flat top part, narrow bottom part and thick middle. It has triangle form in transverse section.

Lungs. The left lung of Manchurian wapiti has three lobes, right one has four lobes, connective tissue is well-developed, lobulation is clear on cross section. Tracheal bronchus is separated from trachea before bifurcation to the cranial part of cranial lobe.

In horse left lung has two lobes, right lung has three. Connective tissue of lungs is pure developed, lobulation on cross section is not clear, tracheal bronchus is absent.

Heart. There are two heart bones at a foot of aorta in Manchurian wapiti.

There are two or three heart cartilages at a foot of aorta in a horse.

Lymphatic nodes. In Manchurian wapiti they are represented by unified compact organs, which are situated in different parts of a body or on internal organs.

In horse each lymphatic node is represented by a group of lymphatic nodes, which consist of a number of nearby small lymphatic nodes.

Stomach and intestine. Stomach of Manchurian wapiti, as in other ruminants, is referred to multi-chambered type, it consist of rumen, reticulum, omasum and abomasum. The main particularities of Manchurian wapiti's intestine, as in other deer, is that diameter of a small intestine exceeds diameter of a large intestine. Large intestine resembles a scroll, situated in the right half of an abdomen. Jejunal loops are situated at the periphery of this scroll.

Stomach of a horse is one-chambered with relatively small size. Large intestine has a form of two half-loops, it's diameter is considerably superior to the diameter of a small intestine.

\section{Conclusion}

Obtained results of the conducted researches help us to identify truly horse meat from wild meat, in particularly of Manchurian wapiti. Proposed methods of researches can be used not only for meat species determination of the whole animal carcasses, but also for examination of small parts of animal body. It has great importance for the conducting of forensic and veterinary researches, when the number of body parts can be finite. The greatest efficiency can be reached only with complex use of enumerated methods.

One of the most often cases of adulteration of meat production is substitution of wild animal meat for domestic animal meat, for example for horse meat or beef, as the cost of horsemeat is cheaper than the cost of wild animal meat. In veterinary and sanitary expertise various methods of meat species identification are used, which are mostly based on the analysis of anatomical features of different animals body structure. It helps us to control positively the attempts of meat products adulteration from unfair sellers.

\section{References}

1. N.V. Momot, Yu.A. Kolina, I.L. Kamliya, Scientific notes of the Kazan State Academy of Veterinary Medicine named after N. E. Bauman, 244 (4), 121-124 (2020) DOI 10.31588/2413-4201-1883-244-4-121-124.

2. N.V. Momot, Yu. A. Kolina, I. L. Kamliya, Scientific notes of the Kazan State Academy of Veterinary Medicine named after N. E. Bauman, 244 (4), 125-128 (2020) DOI 10.31588/2413-4201-1883-244-4-125-129.

3. N.V. Momot, Yu.A. Kolina, I. L. Kamliya, Scientific notes of the Kazan State Academy of Veterinary Medicine named after N. E. Bauman, 245 (1), 108-112 (2021) DOI 10.31588/2413-4201-1883-245-1-108-112.

4. T.N. Sivkova, Perm Agrarian Bulletin 4 (32), 103-109 (2020) DOI 10.47737/23072873_2020_32_103. 
5. N.A. Struchkov, M.V. Andreeva, Scientific life, 15, 6 (106), 856-863 (2020) DOI 10.35679/1991-9476-2020-15-6-856-863.

6. M.E. Ali, Food Analytical Methods 5 (5), 935 (2012) DOI 10.1007/s12161-011-9357-3

7. A. Doosti, P.G. Dehkordi, E. Rahimi, J. Food Sci. Technol 51 (1), 148-152 (2014) DOI 10.1007/s13197-011-0456-3

8. H. Nakamura, T. Muro, Int. J.Legal Med, 123, 177-184 (2009)

9. Horst Erich König, Hans-Georg Hans-Georg, H. Bragulla, Veterinary Anatomy of Domestic Mammals: Textbook and Colour Atlas, 768 (Schattauer Verlag, 2007)

10. A.S. Ilyashenko, A.A. Lukashin, V.S. Zaborovsky, Automatic Control and Computer Sciences 51 (6), 426-434 (2017)

11. I. Martin, Journal of Animal Science 85(2), 452 (2007) DOI: 10.2527/jas.2006-350

12. L. Zeng, J., Wang, J., Sheng, Q., Gu, \& Y. Hong, J. Mitochondrial DNA, 23 (3), 187200 (2012) DOI:10.3109/19401736.2012.668893

13. K. Pickering, C.L. Evans, K.D. Hargin, C.A. Stewart, Meat Sci. 40 (3), 319-326 (1995) DOI: 10.1016/0309-1740(94)00062-c

14. L.V. Utkin, N.V. Simanova, International Journal of Information Technology and Decision Making 11 (2), 307-326 (2012) https://doi.org/10.1142/S0219622012400044

15. L.V. Utkin, F.P.A. Coolen, Interval-valued regression and classification models in the framework of machine learning, In the collection of articles: ISIPTA 2011 Proceedings of the 7th International Symposium on Imprecise Probability: Theories and Applications, 371-380 (2011) 